\title{
O EFEITO RETROATIVO DE UM EXAME DE PROFICIÊNCIA PARA PROFESSORES
}

RODRIGO NASCIMENTO DE QUEIROZ' DOUGLAS ALTAMIRO CONSOLO"

I Universidade Federal do Acre (UFAC), campus Floresta - Cruzeiro do Sul-AC, Brasil; Universidade Estadual Paulista "Júlio de Mesquita Filho" (Unesp), São José do Rio Preto-SP, Brasil; rodrigo.queiroz@ufac.br

II Universidade Estadual Paulista "Júlio de Mesquita Filho" (Unesp), São José do Rio Preto-SP, Brasil; douglas.consolo@unesp.br

\section{RESUMO}

0 presente artigo aborda questões relativas ao efeito retroativo em torno da experiência durante a aplicação do Exame de Proficiência para Professores de Língua Estrangeira (EPPLE). O debate está ancorado nos seguintes princípios: a) a avaliação no ensino $e$ aprendizagem de línguas; b) a proficiência linguístico-comunicativo-pedagógica (PLCP) de professores de línguas; e c) as experiências materializadas como efeitos retroativos na prática avaliativa. A abordagem qualitativa auxilia na interpretação das narrativas de dois professores de Língua Inglesa (LI). A análise interpretativa dos aspectos discursivos indica que os impactos possibilitam o resgate da consciência reflexiva inter-relacionada com as memórias da formação profissional, assim tornando a experiência concreta e válida para o processo de socialização dos conhecimentos específicos do contexto pedagógico de professores de LI.

PALAVRAS-CHAVE FORMAÇÃO DE PROFESSORES • LÍNGUA INGLESA - PROFICIÊNCIA LINGUÍSTICO-COMUNICATIVO-PEDAGÓGICA • EXAME DE PROFICIÊNCIA. 


\section{EL EFECTO RETROACTIVO DE UN EXAMEN DE COMPETENCIA PARA PROFESORES}

RESUMEN

El presente artículo aborda temas relativos al efecto retroactivo en torno a la experiencia durante la aplicación del Examen de Competencia para Profesores de Lengua Extranjera (EPPLE). El debate se basa en los siguientes principios: a) la evaluación en la enseñanza y aprendizaje de idiomas; b) la competencia lingüístico-comunicativo-pedagógica (PLCP) de profesores de idiomas; y c) las experiencias materializadas como efectos retroactivos en la práctica evaluativa. El abordaje cualitativo auxilia en la interpretación de las narrativas de dos profesores de Lengua Inglesa (LI). El análisis interpretativo de los aspectos discursivos indica que los impactos posibilitan el rescate de la consciencia reflexiva interrelacionada con las memorias de la formación profesional, haciendo de esta forma que la experiencia sea concreta y válida para el proceso de socialización de los conocimientos específicos del contexto pedagógico de profesores de LI.

PALABRAs clave FORMACIÓN de PROFESORES • LENGUA INGLESA • COMPETENCIA LINGÜÍSTICO-COMUNICATIVO-PEDAGÓGICA • EXAMEN DE COMPETENCIA.

\section{WASHBACK EFFECT OF AN APPLICATION OF A PROFICIENCY EXAMINATION FOR TEACHERS}

ABSTRACT

This paper deals with some issues related to the analysis of two narratives written by in-service and pre-service English language teachers, following an application of a Proficiency Examination for Foreign Language Teachers [Exame de Proficiência para Professores de Língua Estrangeira - EPPLE] in a public university located in the western Amazon. The discussion is based on the following principles: (i) the implications for assessment in the teaching and learning of foreign languages related to the reconstruction and promotion of socialized practices; (ii) the quality of a linguistic, communicative and pedagogical proficiency of foreign language teachers underlying the elements of validity and reliability of EPPLE; and (iii) the intersection of experiences materialized as washback effects from a process of assessment practices. The analysis of the teachers' discourses indicates an intersection between teachers' memories and professional experiences.

KEYWORDS TEACHER TRAINING • ENGLISH LANGUAGE • LINGUISTIC, COMMUNICATIVE AND PEDAGOGICAL PROFICIENCY • PROFICIENCY EXAM. 


\section{INTRODUÇÃO}

A área de pesquisas em torno de aspectos relativos à avaliação no ensino e aprendizagem de línguas estrangeiras encontra-se em crescente fase de profícua produção acadêmica, na medida em que agrega dados gerados em ambiências de investigação, como, por exemplo, a intersecção dos atores e agentes sociais (educadores, aprendizes, coordenadores educacionais, examinadores, elaboradores de exames, dentre outros) envolvidos em diversificadas práticas avaliativas (avaliação de desempenho, somativa, formativa e dinâmica).

Apesar do fértil campo de investigações acerca de particularidades direcionadas à avaliação no ensino de línguas, um quantitativo representativo de profissionais da área da educação ainda desconhece o papel social da avaliação no alicerce do processo de ensino e aprendizagem. Em geral, pesquisadores das áreas da Educação e da Linguística Aplicada apontam para lacunas presentes no nível de informação e formação de professores de línguas, no que concerne à intercompreensão das relações dialógicas (ABRAHÃO, 2014; 
CONSOLO; TEIXEIRA DA SILVA, 2014; HOFFMAN, 1994; PERRENOUD, 1999) subjacentes à prática de avaliação.

Um dos fatores em debate no presente artigo está direcionado às implicações epistemológicas e práticas balizadas pelas representações cristalizadas acerca da avaliação no ensino de línguas nas licenciaturas de formação de professores.

Nessa perspectiva, este artigo intenciona, de modo preliminar, identificar e apontar aspectos de ordem positiva e negativa, no que concerne ao efeito retroativo face a uma experiência de aplicação de um exame de proficiência, registrada em excertos de narrativas produzidas por professores de Língua Inglesa (LI) em formação inicial, por sua vez intermediadas pela ação experiencial materializada nos indícios linguísticos e discursivos. Desse modo, a proposta de análise enfoca os efeitos retroativos que possam surgir durante a participação no intercurso da aplicação de um Exame de Proficiência para Professores de Língua Estrangeira (EPPLE) a esses professores.

A justificativa para o enfoque nessa temática está fundamentada na necessidade de defender uma formação de professores de línguas estrangeiras, em específico de LI, acerca do desenvolvimento contínuo das competências profissionais e de uma qualidade adequada no que diz respeito à proficiência linguístico-comunicativo-pedagógica (PLCP) (CONSOLO; TEIXEIRA DA SILVA, 2014, 2016). Na sequência, estão apresentadas algumas das complexidades correspondentes ao contexto escolhido, e que, por sua vez, motivam o debate neste artigo:

a. a ausência de uma formação docente adequada relativa à avaliação no ensino de línguas;

b. a inclusão, nos cursos de formação de professores, de instrumentos de avaliação, neste caso o EPPLE, a fim de figurar como artifício propulsor de metarreflexão contínua dos atores sociais envolvidos na educação de línguas;

c. a intercompreensão das relações estabelecidas pela cultura da reaprendizagem por meio de narração que materializem os movimentos de dimensão experiencial e interpessoal que emergiram nesse processo de pesquisa. 
Os apontamentos sugeridos caracterizam o contexto de formação de professores de LI investigado e a urgência em repensar parâmetros que alicerçam a avaliação. Os artifícios balizadores desse processo de transformação, sugeridos e acessíveis aos atores envolvidos, são responsivos, como, por exemplo, a inserção de disciplina no currículo que contemple um estudo básico sobre as acepções da avaliação (no termo geral e no ensino de línguas).

No entanto, a cultura de uma prática avaliativa embasada na sustentabilidade (BOUD, 2000) da identidade social do sujeito em formação educacional deve conduzir a mudanças representativas no fazer pedagógico do educador. A inserção de uma disciplina no currículo e o fortalecimento do hábito de perscrutar formas diferenciadas de avaliação para que os efeitos sejam de ordem social e cultural na vida do aprendiz podem viabilizar o desmembramento de outros artifícios que sustentam esse posicionamento.

A aplicação do EPPLE e a produção das narrativas exemplificam esses artifícios que conduzem para o desvelar de um efeito retroativo possível e, por conseguinte, caracterizam dados para o desenvolvimento de estudos, bem como para a implementação de políticas coerentes na área da avaliação do ensino e da aprendizagem de línguas estrangeiras.

$\mathrm{O}$ artigo está organizado em quatro seções principais. A primeira versa acerca de acepções teóricas, tendo como fio condutor a avaliação no ensino de línguas estrangeiras, seguida por uma breve discussão sobre as competências e a proficiência do professor de LI e aspectos do efeito retroativo. Na segunda seção, é apresentado o modus operandi da sistematização metodológica, com a descrição do contexto e respectivos participantes, bem como dos instrumentos aplicados para a produção dos dados. A terceira seção traz a discussão dos dados, organizados em dois eixos categóricos distintos, os quais intersecionam aspectos de efeitos retroativos resultantes da aplicação do EPPLE. Na quarta seção, são tecidas considerações preliminares que dinamizam a continuidade da presente discussão em um plano macro, em nível de uma pesquisa de doutorado em andamento. Uma resenha com teor responsivo é abordada no fechamento deste artigo. 


\section{APORTES TEÓRICOS}

Nesta seção, são apresentados os fundamentos epistemológicos que sustentam as proposições discutidas neste artigo. $\mathrm{O}$ aporte teórico estabelece um diálogo sobre a avaliação no ensino de línguas estrangeiras, por meio da conexão dos pontos a seguir:

a. compreensão dos processos de formação de professores de LI, alicerçados pela perspectiva sociocultural (ABRAHÃO, 2014; JOHNSON; GOLOMBEK, 2016; LANTOLF; POEHNER, 2014);

b. desenvolvimento e fortalecimento das competências profissionais como motivação para a qualidade da PLCP do professor de LI (CONSOLO; TEIXEIRA DA SILVA, 2014, 2016);

c. algumas considerações conceituais sobre o efeito retroativo (QUEVEDO-CAMARGO, 2014; SCARAMUCCI, 2004).

Para visualizar o dialogismo de interconexão dos fundamentos teóricos, apresentamos, na Figura 1, a seguir, um resumo em forma de diagrama:

FIGURA 1 - Diálogos e intersecções teóricas

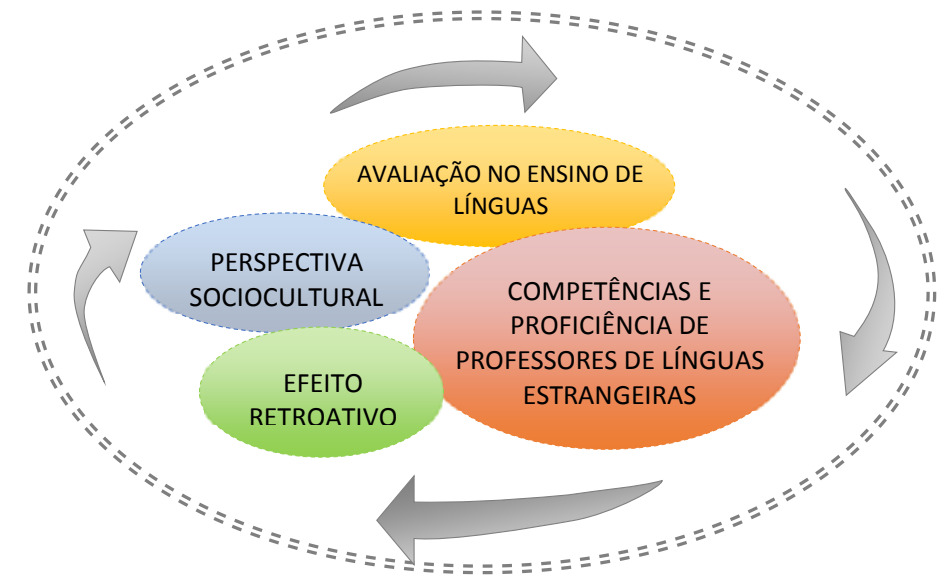

Fonte: Elaboração dos autores.

O diagrama apresenta o arcabouço teórico, o qual entrelaça as perspectivas epistemológicas evocadas para a intercompreensão da problemática aqui apontada, no contexto de 
formação de professores de LI. O conglomerado de teorias, cada um com cores representativas diferenciadas, sintetiza o posicionamento discursivo determinado por evocações de estudos científicos, uma vez que concede validade à tessitura deste artigo. As setas representam a intersecção dos diferentes aportes teóricos, dado que propiciam a dinâmica de trocas de ideias para a materialização da discussão coerente e crítica acerca da prática avaliativa na formação de professores de LI.

\section{PRÁTICAS DE AVALIAÇÃO NA FORMAÇÃO DE PROFESSORES DE LÍNGUA INGLESA}

Pesquisadores tais como Lantolf e Poehner (2005), Luckesi (1996), Perrenoud (1999) e Scaramucci (1999) assinalam a importância da avaliação como suporte de integração de práticas sociais no desenvolvimento cultural e intelectual dos sujeitos, em contextos de ensino e aprendizagem, como agentes educacionais e aprendizes. De modo geral, a avaliação pressupõe a aplicação de atividades que demandam retornos acumulativos, como a representação do desempenho do processo de ensino e aprendizagem por meio de médias aritméticas. Esse fator permanece atrelado à dicotomia pautada na punição versus nível de conhecimento, praticada por professores com formação insuficiente no que concerne a questões relativas à práxis avaliativa (McNAMARA, 2001).

Dentro dessa perspectiva, essa subseção aborda duas questões fundamentais: a reconstrução de práticas avaliativas coerentes com a realidade do ensino de línguas estrangeiras; e as formas pelas quais os professores de LI podem mediar o processo de aprendizagem por meio da interface abordada na perspectiva sociocultural. Para tanto, o aparato teórico está figurado pelos conceitos que racionalizam a formação do professor para um desenvolvimento sistemático, intencional e orientado a partir de objetivos consistentes com a formação docente.

De acordo com Abrahão (2014, p. 17-18), apoiada em Johnson e Golombek (2011), a perspectiva sociocultural, como teoria da mente, intenta compreender o percurso 
processual vivenciado pelo professor. Para atingir os objetivos dos estágios de formação inicial e continuada representados pela carreira docente e as histórias de vida, também pode sinalizar os percursos e indícios para um mapeamento dos momentos de (re)aprendizagem e (co)construção para um futura prática efetiva na educação. De certo modo, o cerne do debate acerca de práticas tradicionais na avaliação, em específico no ensino e aprendizagem de LI, contingencia preocupações crescentes para mudanças que acompanhem as urgências da contemporaneidade. Nesse sentido, a polarização de uma ambientação cunhada na posicionamento responsivo em torno de realidades sociais e culturais distintas possibilita rearranjos nas inferências e crenças produzidas por professores de LI em fase de formação contínua.

As propostas articuladas por Boud (2000) e McNamara (2001) apontam para o fator da sustentabilidade na avaliação, ou seja, uma formação ativa para os atores sociais relativa ao acompanhamento contínuo das práticas vivenciadas em ambiências formais e informais da vida cotidiana. Dessa maneira, este artigo textualiza e interpreta o valor da prática de avaliação no ensino de LI pelo viés participativo e dinâmico, que, por sua vez, possibilita promover a constituição de vias de acesso para a reconstrução da consciência profissional e interpessoal do professor de LI em formação.

Ainda conforme Abrahão (2012), a teoria sociocultural alicerça os professores no agir pelo reconhecimento de fragilidades e consistências de práticas para que, assim, perpassem pelo processo de reconstituição, ou seja, o modelo de agenciamento humano. Os aspectos de cognição, em conjunção com o fazer nas tarefas do cotidiano, condicionam essa perspectiva como essencial para mapear como os professores compreendem a si e aos atores sociais (aprendizes e agentes educacionais) de contextos de ensino em específico.

Johnson e Golombek (2016), com base em uma teoria da mente, reforçam que a conceptualização oriunda das proposições de Vygotsky $(1978,1986)$ possibilita interpretar o desenvolvimento da cognição humana corporificada pelo processo de reflexão interna e externa. O decurso dessa ação promove a mediação dos artefatos simbólicos, construídos 
1 Do original: "individuals as actors in and on the social situations in which they are embedded, being both shaped by and shaping the social situations of cognitive development". no escopo social e cultural regulado por conceitos e atividades para, assim, delimitar espaços do mundo material. Em complemento a essa proposição, as autoras reconhecem:

[...] os sujeitos como atores na e em situações sociais, pelas quais estão envoltos, ao passo que são constituídos e constituem as situações sociais de desenvolvimento da cognição. (JOHNSON; GOLOMBEK, 2016, p. 2, tradução livre) $)^{1}$

De maneira objetiva, os sujeitos históricos e humanos, nesse caso, os professores de LI, estão construídos pelo agir de suas experiências internalizadas e externalizadas como aprendizes em práticas culturais cingidas na formação docente.

A observação da internalização do processo de formação, segundo a perspectiva sociocultural vygotskiana, advém da observação (apprenticeship of observation), termo em paralelo com os estudos propostos por Lortie (1975), na medida em que está instanciado com a vivência no contexto de ensino em relação aos símbolos constituídos pelo mundo. O autor ainda pontua que os professores em formação ingressam nos cursos com ausência de conhecimento acadêmico, na medida em que têm conhecimento superficial acerca de teorias e práticas concernentes à linguagem, assim tornando as ligações com o processo pedagógico inconsistentes e distantes da realidade social (ABRAHÃO, 2012). Contudo, para que seja possível compreender o intercurso de desenvolvimento cognitivo do professor em formação, Johnson e Golombek (2016), apoiadas na teoria vygotskiana, apresentam dois tipos de conceitos simbólicos - científicos (academic concepts) e cotidianos (everyday concepts). Esses conceitos compõem parte do arcabouço teórico sobre o qual as autoras alicerçam os estudos inseridos na teoria da perspectiva sociocultural. De acordo com Johnson e Golombek (2016, p. 2), embasadas em Lortie (1975) e Vygotsky (1986), os conceitos científicos e cotidianos estão relacionados aos conceitos de ordem real ou conceitos reais (true concepts), para que assim a regulação do conhecimento e aprendizagem estejam em equilíbrio contínuo e o ensino seja um fenômeno que emerja das experiências 
de vida. Partindo dessa conjunção de conceitos para os contextos da aprendizagem do professor, os conceitos acadêmicos estão sintetizados de maneira gradual em fenômenos concretos e, por conseguinte, os conceitos cotidianos perpassam os fenômenos em consonância com as generalizações. Em geral, esses conceitos permeiam a trajetória construída pelo profissional docente face aos enfrentamentos da prática de ensino, seja nos contextos da sala de aula, seja nos entornos da vida social.

Johnson e Golombek (2016, p. 2) ainda afirmam que a internalização desses conceitos possibilita que as ações do professor perpassem por um processo de (re)aprendizagem, uma vez que também permitem iluminar a reflexão sobre as ações vivenciadas na relação entre professor e aprendiz. Na percepção das autoras, os conceitos reais auxiliam na mudança do pensamento e das crenças adquiridas pelo professor em sua história de vida e formação educacional. Ao instrumentalizar no nível psicológico a junção desses conceitos, por sua vez associados aos aspectos oriundos da teoria, o professor em formação contínua visualiza de maneira concisa as práticas do contexto de aprender e ensinar.

De algum modo, a perspectiva sociocultural poderá apontar caminhos de acesso para que o processo de aprendizagem do professor de LI em formação estabeleça relações com o conhecimento apreendido nas experiências cotidianas, ou seja, uma busca por mediação entre os conceitos do cotidiano e os conceitos científicos. A conexão dos conceitos e símbolos presentes no cognitivo dos professores de LI, participantes dessa experiência, possibilitam a visualização de elementos que compõem o efeito retroativo da avaliação. Esses aspectos, por sua vez, favorecem o surgimento do processo de mediação da aprendizagem dos professores de LI, em parte do grupo de participantes deste estudo, para que possam revitalizar o foco para o desenvolvimento contínuo das competências e da PLCP. 


\section{COMPETÊNCIAS E PROFICIÊNCIA DO PROFESSOR DE LÍNGUA INGLESA}

A qualidade do professor de línguas estrangeiras, em sua natureza de formação, deve contemplar aspectos nas dimensões de competência e proficiência. Assim, as características abordadas nesse subitem estão embasadas nos conceitos por Consolo e Teixeira da Silva $(2014,2016)$ e Teixeira da Silva (2014). Para tanto, uma breve proposta de articulação será apresentada a partir da conjunção dos construtos teóricos e de uma análise com exemplos advindas dos relatos das experiências dos professores em formação inicial que participaram do EPPLE.

$\mathrm{O}$ aprendizado de uma língua estrangeira pode representar a inserção dos atores sociais (professores e aprendizes) em práticas culturais engendradas por usos adequados e eficientes em situações comunicativas distintas. Essa sucinta exemplificação aponta o papel do professor de LI no aperfeiçoamento da qualidade das competências e da PLCP, presentes nas dimensões de uso real, no que concerne à performance de tarefas cotidianas em sala de aula. Um objeto motivador nessa práxis é o EPPLE, destacado como um exame que busca a qualificação integralizada de duas habilidades justapostas, a escrita e a oral, na medida em que propõe a ressignificação do aspecto formativo do professor de LI nas licenciaturas no Brasil.

Em defesa dessa postura científica e acadêmica para uma sólida formação de professores de LI, Consolo e Teixeira da Silva $(2014$, p. 66) postulam que é essencial o:

2 DOUGLAS, Dan. Assessing languages for specific purposes. Cambridge: Cambridge University Press, 2000

ELDER, Catherine. Performance testing as benchmark for foreign language teacher education. Babel. Journal of the Federation of Modern Language Teachers Associations, v. 29, n. 2, p. 9-19, 1994a

ELDER, Catherine. Assessing the language proficiency of teachers: are there any border controls? Language Testing, v. 18, n. 2, p. 149-170, 2001.
[...] empenho na trajetória de investigar, avaliar e definir a PLCP em LE [língua estrangeira] também em termos de um escopo de competência linguística mais ampla ou geral, bem como em termos de uma proficiência para o uso da linguagem oral para finalidade específica de atuar como professor da língua ensinada (DOUGLAS, 2000; ELDER, 1994a, 2001)2 incluindo-se aqui a linguagem pedagógica ou metalinguagem.

Tomando como base as proposições abordadas pelos autores, esta subseção compreende os conceitos de 
competência e PLCP, alicerçados em torno da perspectiva do desenvolvimento de instrumentos avaliativos eficazes na promoção da qualidade do profissional da área de LI. A importância desse exame interfere não apenas no comportamento dos professores de LI, mas também nos atores sociais (professores formadores, pesquisadores) que atuam no escopo de formação e de investigações da área de formação de professores.

Dessa forma, a competência é um dos eixos de ligação que determinam e possibilitam os usos e fazeres com a língua, ou seja, seria o lugar no qual coabita um feixe de capacidades performáticas e requeridas para um profissional de ensino eficiente. Teixeira da Silva (2014) reúne algumas concepções de teóricos da área de estudos da linguagem para compreender as contribuições práticas acerca da competência comunicativa para o ensino de LI. Em geral, é compreensível que, para demonstrar a qualidade e eficiência comunicativa de um profissional no ensino de línguas, o feixe de competências seja movido em fluxo contínuo e ininterrupto. As características que perfazem a competência serão discutidas a partir de uma visão crítica, ancorada nos autores apresentados neste artigo.

Ainda conforme Teixeira da Silva (2014), a competência está atrelada ao desempenho, na medida em que o espectro de ações da competência é abstrato, tornando assim o desempenho, a performance, um ato concreto na realização de tarefas postas como desafio para o sujeito que utiliza a língua em situações comunicativas. Assim sendo, as competências resultam da mobilidade de artifícios armazenados pelo sujeito, que são expressas na performance a partir das necessidades de ordem linguística e comunicativa. Esse dado conduz à interpretação de que o EPPLE mantém os princípios construtivos de constituir um perfil de professor de LI em condições adequadas de atuação, uma vez que os testes que compõem o exame - a saber, um teste oral e um teste escrito - propõem visualizar, por meio de tarefas, as competências correspondentes a um profissional qualificado e motivado para o ensino de línguas.

Para esclarecer como tais impactos influenciam na relação entre o EPPLE e a qualidade do PLCP dos professores de LI, 
na seção seguinte, esses aspectos serão apresentados a partir da conceituação das características do efeito retroativo.

\section{O EFEITO RETROATIVO NO ENSINO DE LÍNGUAS}

Delimitar o escopo das condições pelas quais práticas de avaliação, tais como exames, testes e provas, implicam o comportamento e as ações dos atores sociais em contextos de ensino ainda possui um intenso grau de complexidade conceitual. Pesquisadores da área de avaliação no ensino de línguas têm desenvolvido estudos crescentes acerca desse construto teórico e dos impactos oriundos dos exames, testes e provas. É visível, portanto, que estudos sobre o nível de impacto e as influências durante a situação da aplicação das avaliações, associados aos comportamentos dos participante, referendam a necessidade de compreender a intensidade promovida por este evento, ou seja, à qual proporção estes elementos representam um efeito retroativo (washback effect ou backwash effect). Na tentativa de apresentar uma compreensão geral do efeito retroativo na avaliação em situações de ensino de línguas, esta subseção será embasada em Quevedo-Camargo (2014) e Scaramucci (2004).

O debate, por sua vez, indica a necessidade de desenvolver a centralidade do conceito de efeito retroativo, assim considerando aspectos de ordem contextual e comportamental dos atores envolvidos em processo avaliativo. Desse modo, Scaramucci (2004) ressalta que:

\footnotetext{
Entender melhor o conceito de efeito retroativo pressupõe compreender os mecanismos operantes na relação entre ensino/aprendizagem e avaliação que, de acordo com Bachman and Palmer (1996), é muito mais complexa do que apenas a influência de um teste no ensino e aprendizagem. O impacto teria, neste caso, de ser avaliado com referência às variáveis, objetivos e valores da sociedade, do sistema educacional em que é usado, assim como dos resultados potenciais de seu uso. (SCARAMUCCI, 2004, p. 204-205)
} 
A proposta implantada pelo grupo de pesquisadores do EPPLE fundamenta-se na afirmação da autora (SCARAMUCCI, 2004), na medida em que apresenta uma dimensão de abrangência conceitual do efeito retroativo, enfocando o conglomerado de crenças, percepções e conhecimentos (conceitos do cotidiano e científicos) dos atores sociais participantes do evento de avaliação. Na maioria dos contextos de ensino, o efeito retroativo fluirá de formas distintas, que, por conseguinte, podem materializar influências de ordem positiva e negativa. É necessário que os sistemas de avaliação no ensino de línguas possuam uma diretriz, dependendo das particularidades contextuais e do construto teórico direcionado para o aspecto em específico que se propõem a avaliar. Dessa maneira, os efeitos/impactos poderão apresentar um panorama dos aspectos que necessitam tratamento controlado, no que concerne às dificuldades no processo de ensino e aprendizagem de línguas, por exemplo, acerca da proficiência linguística, da competência escrita e da leitura, dentre outros elementos que compõem a qualidade formativa do professor de LI.

Quevedo-Camargo (2014), com base nos aportes teóricos da avaliação no ensino de línguas, sustenta que a aproximação dos mecanismos do efeito retroativo com as abordagens de ensino surgiu com o progresso de implementação das abordagens de ensino marcadas pela presença e influência de "regras gramaticais pseudocontextualizadas" (QUEVEDO-CAMARGO, 2014, p. 87). Ainda conforme a autora, os exames e provas escolares, apesar de intencionarem representar tarefas de ordem comunicativa, preconizam o enfoque em estruturas da língua. É necessário, então, um prisma apurado sobre duas dimensões que compõem o processo ensino/ aprendizagem e avaliação, ou seja, os agentes educacionais e os aprendizes, ao passo que os graus de efeito retroativo possam ser explorados a partir de uma ação direcionada para o contexto de práticas sociais sustentáveis.

De acordo com Scaramucci (2004) e Quevedo-Camargo (2014), no escopo de estudos internacionais, em meados dos anos 1990, o conceito de efeito retroativo era concebido como um fenômeno determinista e a questão girava em torno da metáfora de impactos negativos que influenciavam 
professores e aprendizes. Os estudos, por sua vez, contribuíram com modelos de intercompreensão dos mecanismos do efeito retroativo: modelo básico (BAILEY, 1996), modelo estímulo e resposta, modelo de inovação do currículo (BURROWS, 2004) e dimensões na composição do efeito retroativo (WATANABE, 2004). E, ainda, com dados empíricos sobre evidências de impactos de exames e testes em contextos de ensino e aprendizagem.

No Brasil, as pesquisas iniciaram-se no fim dos anos 1990 e contribuíram para o crescimento dessa linha na área da Linguística Aplicada (LA). Os estudos de Scaramucci (2004) foram os primeiros no auxílio do aprofundamento para entender o fenômeno do efeito retroativo em práticas avaliativas, como, por exemplo, os vestibulares e exames nacionais. As orientações em nível de mestrado e doutorado também possibilitaram revelar aspectos empíricos acerca das práticas de avaliação nos contextos da sala de aula. O debate acerca da importância de articular o conhecimento teórico e prático sobre a avaliação no ensino de línguas para os aspectos do efeito retroativo, por sua vez, torna-se essencial para produzir práticas reflexivas para a formação de professores de línguas e para o contexto educacional acerca das relações dinâmicas que compõem o processo de ensino e aprendizagem.

O recorte intencionado para esta subseção aborda somente aspectos mais gerais, para que complementem a metarreflexão em torno das ações implementadas pelo EPPLE na defesa da qualidade para desenvolvimento da PLCP do professor de LI. As experiências de participação no EPPLE são elementos que materializam os possíveis efeitos retroativos quanto à ação comportamental, seja negativa ou positiva, demonstrada pelo registro escrito dos participantes. De alguma forma, essa ação reflexiva contribui para a continuação do debate acerca da necessidade de implementar e aprimorar instrumentos que engajem a classe de pesquisadores para a produção científica de estudos relativos ao nível de qualidade da proficiência e competência do professor de línguas. 


\section{METODOLOGIA DA INVESTIGAÇÃO}

Esta investigação está caracterizada como qualitativa, de enfoque etnográfico, sendo desenvolvida no contexto de aplicação de um exame com propósitos definidos para avaliar as competências e a PLCP do professor de LI (CONSOLO; TEIXEIRA DA SILVA, 2014).

Para os propósitos definidos neste artigo, a categorização dos dados constituídos durante o processo de aplicação da metodologia de pesquisa objetivou a aproximação dos seguintes proposições:

a. apresentar exemplos de evidências de um efeito retroativo por meio de elementos linguísticos e discursivos materializados nas narrativas dos professores de LI (participantes);

b. articular as experiências materializadas nas narrativas escritas com os tipos de reações/impactos e percepções/conhecimento de conceitos para discutir possibilidades de mediação da reaprendizagem nas práticas sociais e avaliativas dos atores envolvidos (professor-participante e professores de LI).

Na tentativa de conciliar o aporte teórico com a proposta de articulação desta pesquisa, a geração dos dados seguiu uma organização metodológica ilustrada na Figura 2:

Figura 2 - Sistema de aplicação da metodologia

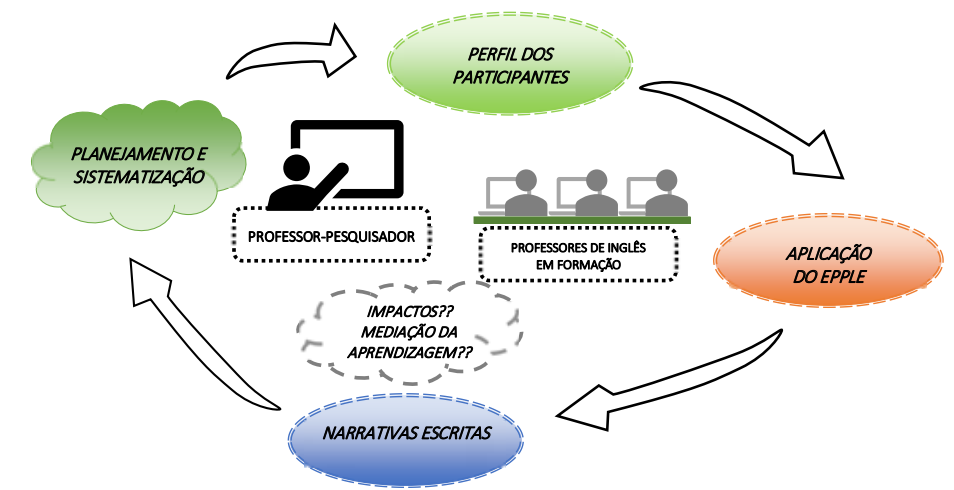

Fonte: Dados da metodologia da pesquisa.

As etapas da coleta dos dados compreenderam a sequência abaixo. 
Etapa I - Planejamento e sistematização: a aplicação do EPPLE foi realizada em meados de abril de 2016 no campus de uma universidade pública federal do interior da Amazônia Ocidental. O laboratório de informática do campus foi disponibilizado para a instalação do programa de suporte e geração dos dados do EPPLE. O laboratório possui 43 máquinas com conexão à rede de internet, sendo que uma é reservada para o usuário (tutor ou professor). Para que a execução do EPPLE se desse na data agendada, com o auxílio do técnico de laboratório, o programa foi instalado em 20 máquinas (sendo que duas foram resguardadas caso ocorresse algum problema técnico), considerando-se a quantidade de candidatos (18) para realizar o exame. As 18 máquinas foram cadastradas com código e registradas com o número de CPF de cada candidato, seguindo protocolos de segurança.

Etapa II - Perfil dos participantes: a este universo correspondem 10 professores de LI em formação que foram convidados para o exame. Como referencial para posterior análise dos dados, o grupo foi dividido em: grupo A - quatro professores de LI em formação inicial, de períodos distintos de Licenciatura em Letras Inglês; grupo B - seis professores de LI em serviço. A faixa etária em ambos os grupos era de 21 a 35 anos, sendo que todos frequentam e/ou foram graduados no curso de Letras Inglês da instituição pública de ensino superior que sediou a aplicação do EPPLE.

Etapa III - EPPLE: como mencionado em seções anteriores e conforme Consolo e Teixeira da Silva (2014), o EPPLE objetiva avaliar a capacidade de uso comunicativo da língua em contextos de sala de aula, como, por exemplo, apresentar instruções. O EPPLE possui um corpo de testes (escrito e oral) constituído de tarefas comunicativas embasadas no contexto de prática pedagógica para o uso linguístico e comunicativo do professor de LI. O insumo linguístico das tarefas é formulado por meio de temas do contexto de ensino de línguas e gêneros multimodais (vídeos, áudios e textos) para auxiliar na análise e resolução por parte dos candidatos. $\mathrm{O}$ exame aplicado nesta pesquisa possui o mesmo formato e durou aproximadamente duas horas. Todo o processo ocorreu dentro da regularidade; no entanto, somente um computador apresentou um problema de geração do vídeo 
em uma das tarefas do teste oral, que foi resolvido a tempo, com a mudança do candidato para outra máquina.

Etapa IV - Narrativas escritas: Quevedo-Camargo e Scaramucci (2016) afirmam que a descrição de experiências por meio de diários escritos possui o mérito de capturar nuances imperceptíveis ou inobserváveis, na medida em que as narrativas também podem estar conciliadas com outros instrumentos de captura de dados. Esse instrumento foi utilizado seguindo essa premissa e, ainda, por permitir o confronto de crenças e reflexões oriundas dessa prática de pesquisa. Outro aspecto está relacionado ao registro de itens linguísticos e discursivos que esquematizam o percurso do processo cognitivo dos participantes e que podem ainda desvelar indícios do efeito retroativo. As narrativas escritas foram produzidas pelos participantes a partir de uma única questão balizadora - "Como você avalia a experiência de participar desse tipo de exame?”. A opção por uma única questão é relativa à produção escrita livre para que os participantes pudessem se sentir confortáveis em expressar as experiências partindo de ângulos e pontos de vista considerados significativos durante a participação no EPPLE.

O modelo adotado para propósitos de análise está baseado nos estudos de Bailey (1996), que envolve participantes, processos e produtos, os quais podem ser analisados a partir da materialização dos registros linguísticos e discursivos presentes nas narrativas dos professores de LI que participaram do EPPLE.

\section{DISCUSSÃO DOS DADOS}

A análise dos dados está centrada em três categorias adaptadas do modelo proposto por Bailey (1996) para evidenciar aspectos do efeito retroativo. Aspectos aliados aos conceitos do cotidiano e científicos (JOHNSON; GOLOMBEK, 2016) serão observados quanto à inferência apresentada na discussão dos elementos linguísticos e discursivos materializados nas narrativas escritas.

Na subseção seguinte, serão analisados dois excertos de narrativas, apontando-se itens linguísticos e discursivos do efeito retroativo por meio da relação dialógica dos atores 
sociais envolvidos na avaliação. A identidade dos participantes está resguardada, sendo estes reconhecidos pela sigla que diferencia professor de LI em formação inicial (PLIFI 1, PLIFI 2...) e professor de LI em serviço (PLIS 1, PLIS 2...).

Conforme Abrahão (2014) e Johnson e Golombek (2016), a manifestação das emoções e sentimentos imbricados no processo de reconstrução da aprendizagem dos professores em formação simboliza um artefato essencial para que os conceitos de ordem cotidiana e científica desenvolvam um novo prisma sobre a realidade experienciada. As narrativas escritas que compõem o conjunto de dados deste estudo desvelam, a partir de um aspecto mais global, particularidades anunciadas pelos autores. Esse exemplo está corporificado no excerto seguinte:

[... (1) me senti muito frustrada por não ter um rápido raciocínio para responder as questões em tempo hábil e sem materiais de consulta, principalmente as questões que envolviam a habilidade de 'speaking'. No momento do teste também (2) senti a diferença do meu papel social de aluna de graduação para professora de Língua Inglesa. (3) Eu já havia feito o teste do TOEFL e tinha achado difícil, mas a prova EPPLE me fez refletir sobre todos os requisitos que um professor de Língua Inglesa deve pensar, refletir, estudar e aplicar em suas aulas para que possa proporcionar aos seus alunos 'os caminhos' da aprendizagem. Nesse sentido, percebi que em relação aos (4) fatores didáticos como os motivacionais e de autonomia no processo de ensino e aprendizagem, eu consegui desenvolver bem durante o curso de graduação, apesar de o conhecimento ser um processo diário da teoria e da prática [...]. (PLIS 1, grifos dos autores)

No excerto da narrativa de PLIS 1, podemos observar quatro partes distintas reveladas por um percurso de metarreflexão inicial vivenciadas no cotidiano da formação acadêmica e profissional. Na parte 1, "me senti muito frustrada", o PLIS 1 desvela um aspecto do efeito retroativo relativo às ações atitudinais que podem desencadear a desmotivação por não se conseguir articular a dimensão cognitiva com os conceitos cotidianos e científicos apreendidos durante a 
formação inicial. A diferença sobre os papéis sociais atribuídos na história de formação também pode representar um elemento do efeito retroativo, como observado na parte 2 , "senti a diferença do meu papel social". É possível inferir que o paralelo entre os mundos da vida acadêmica e da cultura da sala de aula emerge quanto da exigência da resolução das tarefas propostas pelo EPPLE. O despertar da metarreflexão no que concerne à autonomia do aprender, estudar e aplicar na prática os conceitos reais (JOHNSON; GOLOMBEK, 2016) é materializado na parte 3: "Eu já havia feito o teste do TOEFL e tinha achado difícil, mas a prova EPPLE me fez refletir sobre todos os requisitos que um professor de Língua Inglesa”. Os requisitos citados por PLIS 1, de fato, coexistem no processo de formação inicial; entretanto, é possível interpretar que o EPPLE, nesse caso, auxiliou no crescimento de um efeito retroativo positivo. Outro aspecto observado é a diferença apresentada entre dois tipos distintos de exames para aferir níveis de uso da proficiência. A parte 4, "fatores didáticos como os motivacionais e de autonomia no processo de ensino e aprendizagem, eu consegui desenvolver", aponta que qualidades como motivação e autonomia unem-se com os conceitos da realidade do ensino, na medida em que o desenvolvimento decorre de construção por entre a avaliação.

O ciclo de aspectos do efeito retroativo também é movido pelos itens linguísticos e discursivos da narrativa de PLIS 1. Os participantes (professor/aprendiz, candidato avaliado) são identificados em "me senti muito frustrada, senti a diferença do meu papel, me fez refletir" e revelam, em certa medida, a experiência vivida de forma intensa, o que pode, de algum modo, motivar o professor a perceber suas próprias deficiências, no sentido de buscar o aperfeiçoamento contínuo. O processo exemplificado em "proporcionar aos seus alunos" pode representar um aspecto impulsionador de mudanças de práticas socializadas na cultura da sala de aula de LI, assim envolvendo os atores e conectando o fazer no ensino/aprendizagem e na avaliação. A consequente transformação advém da interpretação concebida por PLIS 1 ao entrecruzar seus pensamentos e concepções pessoais/profissionais com o que propõem as tarefas presentes no EPPLE. 
A cadeia de relações do efeito retroativo materializado na narrativa de PLIS 1 demonstra que o EPPLE ocasionou impactos negativos e positivos. Os efeitos negativos conduziram o processo de pensamento de PLIS 1 para um refletir interligado com todos os aspectos e atores sociais. A insuficiência linguística relativa à habilidade do speaking, apontada na narrativa, está relacionada à negação, que, por sua vez, pode conduzir para efeitos positivos (reaprender a pensar, estudar e observar) e futuros reflexos na prática pedagógica.

Na próxima narrativa, serão analisadas questões dicotômicas de PLIFI 1 em torno de uma possível mediação da aprendizagem motivada pelos impactos no decorrer da realização do EPPLE. As partes relevantes para análise serão destacadas no excerto, a seguir:

[...] (1) Eu não tinha noção da minha "proficiência" tão mínima até a realização do teste. Quando iniciou a prova, (2) nas questões orais, senti-me constrangido por não ser capaz de responder em inglês as respostas que eu pensava em português. Outra que também dificultou para mim foi (3) a vergonha de pronunciar as palavras em inglês na sala onde tinham pessoas com o nível de proficiência bem mais elevado que o meu. Por isso, as minhas respostas para as questões orais foram bem curtas ou até não respondi. (4) Quando chegou nas questões objetivas e escritas, já desanimado pelo fracasso com as primeiras questões, eu a fiz com desânimo, sem muito compromisso [...]." (PLIFI 1, grifos dos autores)

A narrativa produzida por PLIFI 1 apresenta um pano de fundo dramático e distante dos efeitos durante o processo da avaliação, como observado nos exemplos discursivos na narrativa de PLIS 1 . De certo modo, as duas narrativas possuem relação com o que Scaramucci (2004) denominou de "forças existentes na sociedade", ou seja, crenças matizadas e cristalizadas pelos aprendizes que vivenciam uma formação de professores de línguas, sem conhecimento linguístico suficiente para uma reconstrução da identidade social e profissional.

Esse fator de influência externa está exemplificado em "Eu não tinha noção da minha 'proficiência' tão mínima". 
Nessa parte da narrativa, é possível evidenciar que PLIFI 1 constrói uma autoavaliação, motivado pela insuficiência linguística e comunicativa requerida nas tarefas da primeira parte do EPPLE, o teste oral. Contudo, mesmo que PLIFI 1 seja um ator social iniciando o percurso de aprendizagem, os conceitos cotidianos e científicos desfocam o real propósito de realizar ou tentar completar as tarefas do EPPLE. As razões para a ausência de motivação podem ser, por exemplo, o desconhecimento da identidade do professor de LI e a contínua reprovação pessoal impactada pela vida acadêmica na licenciatura.

Nas duas partes seguintes, "senti-me constrangido" e "na sala onde tinham pessoas com o nível de proficiência maior que o meu", os elementos discursivos representam que o EPPLE influencia na forma como PLIFI 1 observa as rotinas de um processo avaliativo. Os sentimentos de desconforto podem demonstrar que os desafios enfrentados são refletidos tanto para a resolução das tarefas do exame como também na representação mental de que os "outros" que participam de contexto semelhante têm um nível de proficiência maior. Esse exemplo desvela alguns conflitos, como o desconforto e o medo que o processo de avaliação desperta nos participantes dessa experiência.

A desmotivação é um dos fatores negativos desse processo, exemplo esse observado na parte 4: "Quando chegou nas questões objetivas e escritas, já desanimado pelo fracasso com as primeiras questões, eu a fiz com desânimo, sem muito compromisso". De algum modo, esses impactos materializados pelos termos desânimo, fracasso e sem compromisso podem possibilitar a mediação da aprendizagem de PLIFI 1, quanto da comprovação das fragilidades. Um outro aspecto que possibilita a transformação e reconstrução desse impacto apresentado na narrativa de PLIFI 1 é a mediação e retomada da experiência por meio de socialização, assim conduzindo o participante para um outro percurso, ou seja, uma reversão para que as falhas sejam reconhecidas como aspectos também positivos.

Esta seção apresentou uma breve análise a partir de duas narrativas contrapostas em torno das experiências durante $o$ 
processo de aplicação do EPPLE. Dois aspectos foram marcados distintivamente: um fator de impacto positivo e o outro com resultado negativo. No entanto, essas experiências de algum modo socializaram de maneira cognitiva novos caminhos para a metarreflexão sobre a PLCP do professor de LI. O EPPLE, nessa perspectiva, pode ser considerado um instrumento motivador e impulsionador que conecta o ciclo do ensino/aprendizagem e avaliação nas histórias de vida do professor de LI em sua formação contínua.

\section{CONSIDERAÇÕES FINAIS}

A intenção do artigo foi demonstrar como, a partir de uma aplicação do EPPLE, um instrumento de avaliação específico para um grupo de atores sociais (professores de LI), desvelam-se inter-relações responsivas por meio de elementos discursivos e linguísticos subjacentes aos efeitos retroativos materializados em narrativas escritas.

Na perspectiva de uma conclusão, esta seção apresenta duas dimensões fundamentais, comentadas na sequência: o posicionamento interpessoal dos participantes envoltos no processo de participação do EPPLE; o decurso dos impactos positivos e negativos na inter-relação com a mediação da aprendizagem e reconstrução da identidade profissional dos professores de LI.

A primeira dimensão, assinalada pelas narrativas, está relacionada às experiências registradas pelos participantes em face da resolução das tarefas do EPPLE propostas para avaliar a PLCP do professor de línguas. Os itens linguísticos e discursivos que materializam esse processo explicitam o efeito retroativo em dois graus distintos - o positivo e o negativo. Essa polaridade envolve particularidades emocionais e atitudinais, que, por sua vez, direcionam os participantes a declarar algum modo de transformação no seu contexto de experiência cotidiana e científica. Conforme verificado na análise e discussão de dois excertos de narrativas, os itens linguísticos e discursivos que desvelam essa inter-relação estão materializados no excerto "me senti muito frustrada, senti a diferença do meu papel social, me fez refletir sobre todos os requisitos" (PLIS 1) e em "Eu não tinha noção da minha 
proficiência, senti-me constrangido por não ser capaz de responder" (PLIFI 1). Nos trechos em que PLIS 1 reconfigura seus sentimentos refletidos acerca do uso efetivo da proficiência do professor de LI, podemos observar uma indicação do efeito retroativo que parte do EPPLE, ao passo que interfere também na renovação de seus valores acerca da necessidade de desenvolver de maneira contínua uma prática de avaliação reflexiva de suas competências profissionais. Nas partes da narrativa expressas por PLIFI 1, outro ponto sobre o efeito retroativo remete à análise para compreender o significado presente de "fracasso" na resolução das tarefas do EPPLE. Tal fato, entretanto, pode possibilitar também um suporte para que o processo de reconstrução da identidade profissional e interpessoal seja reavaliado, assim representando uma contribuição para revisar algumas tarefas do exame, tornando os comandos e instruções concisas sobre a avaliação da proficiência do professor de línguas.

A segunda dimensão encaminha a sequência de metarreflexões materializadas pelos participantes acerca da experiência vivida em um contexto de prática de avaliação distinta e específica para aferir a PLCP de professores de LI. A inter-relação dialógica representada nas narrativas referenda a necessidade de incluir instrumentos de suporte para que a reconstrução da aprendizagem seja acessada, uma vez que as percepções e sentimentos dos participantes do processo conduzam a mudanças de maneira coletiva no contexto do estudo.

\section{REFERÊNCIAS}

ABRAHÃO, Maria Helena V. A formação do professor de línguas de uma perspectiva sociocultural. Signum: Estudos de Linguagem, v. 15, n. 2, p. 457-480, 2012.

ABRAHÃO, Maria Helena V. Sessões colaborativas na formação inicial e em serviço de professores de inglês. Revista Horizontes de Linguística Aplicada, v. 13, n. 1, p. 15-39, 2014.

BAILEY, Kathleen. Working for washback: a review of the washback concept in language testing. Language Testing, v. 13, n. 3, p. 257-279, 1996. 
BURROWS, Catherine. Washback in classroom-based assessment: a study of the washback effect in Australian adult migrant English program. In: CHENG, L.; WATANABE, Y.; CURTIS, A. (Ed.). Washback in language testing: research, contexts and methods. New Jersey: Lawrence Erlbaum Associates, 2004. p. 113-128.

CONSOLO, Douglas A.; TEIXEIRA DA SILVA, Vera Lúcia. Em defesa de uma formação linguística de qualidade para professores de línguas estrangeiras: o exame EPPLE. Revista Horizontes de Linguística Aplicada, v. 13, p. 63-87, 2014.

CONSOLO, Douglas A.; TEIXEIRA DA SILVA, Vera Lúcia. Foreign language teachers' proficiency: the implementation of the EPPLE examination in Brazil. In: GITSAKI, Christina; COOMBE, Christine (Org.). Current issues in language evaluation, assessment and testing. Newcastle upon Tyne: Cambridge Scholars Publishing, 2016. p. 201-219.

HOFFMAN, Jussara M. L. Avaliação mediadora: uma relação dialógica na construção do conhecimento. Idéias, São Paulo, n. 22, p. 51-59, 1994.

JOHNSON, Karen E.; GOLOMBEK, Paula R. (Org.). Research on second language teacher education: a sociocultural perspective on professional development. New York: Routledge, 2011.

JOHNSON, Karen E.; GOLOMBEK, Paula R. (Org.). Mindful L2 teacher education: a sociocultural perspective on cultivating teacher's professional development. New York: Routledge, 2016.

LANTOLF, James P.; POEHNER, Matthew E. Dynamic assessment in the language classroom. Language Teaching Research, v. 9, n. 3, p. 233-265, July 2005.

LANTOLF, James P.; POEHNER, Matthew E. (Org.). Sociocultural theory and the pedagogical imperative in L2 education. New York: Routledge, 2014.

LORTIE, Dan. Schoolteacher: a sociological study. London: University of Chicago Press, 1975.

LUCKESI, Cipriano C. Avaliação da aprendizagem escolar. 3. ed. São Paulo: Cortez, 1996.

McNAMARA, Tim. Language assessment as social practice: challenges for research. Language Testing, v. 18, n. 4, p. 333-349, 2001.

PERRENOUD, Philippe. A avaliação entre duas lógicas. In: PERRENOUD, P. Avaliação: da excelência à regulação das aprendizagens - entre duas lógicas. Tradução de Patrícia Chittoni Ramos. Porto Alegre: Artes Médicas Sul, 1999.

QUEVEDO-CAMARGO, Gladys. Efeito retroativo da avaliação na aprendizagem de línguas estrangeiras: que fenômeno é esse?. In: MULIK, Katia Bruginski; RETORTA, Miriam Sester (Org.). Avaliação no ensino-aprendizagem de línguas estrangeiras: diálogos, pesquisas e reflexões. Campinas: Pontes, 2014. p. 1-16.

QUEVEDO-CAMARGO, Gladys; SCARAMUCCI, Matilde. R. V. Methodology in washback studies. In: GITSAKI, Christina; COOMBE, Christine (Org.). Current trends in language evaluation, assessment $\&$ testing: research perspectives. Newcastle upon Tyne: Cambridge Scholars Publishing, 2016. p. 287-304. 
SCARAMUCCI, Matilde R. V. Avaliação: mecanisno propulsor de mudanças no ensino/aprendizagem de LE. Revista Contexturas, São José do Rio Preto, v. 4, p. 115-124, 1999.

SCARAMUCCI, Matilde R. V. Efeito retroativo da avaliação no ensino/ aprendizagem de línguas: o estado da arte. Trabalhos em Linguística Aplicada, Campinas, v. 43, n. 2, p. 203-226, jul./dez. 2004.

TEIXEIRA DA SILVA, Vera Lúcia. Communicative competence in foreign languages - What concept is this? Revista Contexturas, São José do Rio Preto, n. 23, p. 149-160, 2014.

VYGOTSKY, Lev A. Mind in society: the development of higher psychological processes. Cambridge, MA: Harvard University Press, 1978.

VYGOTSKY, Lev A. Thought and language. Cambridge, MA: The MIT Press, 1986.

WATANABE, Yoshinori. Methodoly in washback studies. In: CHENG, Liying; WATANABE, Yoshinori; CURTIS, Andy (Ed.). Washback in language testing: research contexts and methods. New Jersey: Lawrence Erlbaum Associates, 2004. p. 19-36. 